\title{
Editor's Introduction to Volume 6, Issue 1
}

Welkom, أهلا بك, Wamukelekile, Bienvenue, Karibu, Benvenuti, Dobrodošli, Huānying, Bemvindo, Fáilte, Kaabo, Bienvenido, G-day, Akeyi, Välkommen, Selamat Datang, ようこそ ....and... Welcome to the new version of the International Journal of Rural Criminology!

If we actually translated the English word "welcome" into the languages of the 125,000 plus people who previously downloaded articles from the first five volumes of IJRC, we would need to expand the list above to include the languages spoken in 152 different countries of the world. In other words, IJRC is both frequently read and globally read. We sincerely hope that this upgraded version of IJRC will expand its global reach even more.

One big improvement you will witness with the new IJRC is a regular schedule of publications, which will be twice each year. The burden of a single person editing the journal, on top of other duties, created a persistent problem of irregularity. That will change!

In this issue, there is an accumulation of full-length peer-reviewed journal articles and book reviews that have sat too long, collecting "electronic dust" on a flash drive. The next issue (volume 6, issue 2) will clean up the remaining backlog, and from there, manuscripts will be processed on a regular basis.

IJRC is now co-sponsored by International Society for the Study of Rural Crime, the Division of Rural Criminology, American Society of Criminology, and the European Rural Criminology Working Group of the European Society of Criminology.

The new web site for the journal is https://ruralcriminology.org. Please encourage your fellow rural scholars to register for IJRC. It is really quite simple to do. On the top center of the menu bar is the word "Register". Tell your colleagues to go there, and fill in the relevant boxes. Registration requires about 5 - 10 minutes. However, there is one important task that should not be skipped - be sure to "register as" (at the bottom) both a prospective author and possible reviewer, and indicate what topics would be review. This is because the default command is "reader only". Once completed, click "register" in the lower left-hand corner.

Joseph F. Donnermeyer and Alistair Harkness 